\title{
Early Detection of Depression in Women using Machine Learning Methods
}

\author{
Vidya Y., G. T. Raju
}

\begin{abstract}
According to World Health Organisation(WHO), most prevailing mental sickness and leading evidence of disability is Depression. In India Depression is much more prevalent in women of all age groups. Eventhough effectual treatment is noted for Depression, it is not reaching the maximum number of sufferers in both wealthy and pathetic countries. In this respect, many scientific discipline and researchers have been employed to develop Machine Learning models to determine level of Depression. This paper presents background knowledge on depression and useage of machine learning and also review past studies that apply machine learning for determine depression with their merits and demerits.
\end{abstract}

Keywords: Depression detection, Machine Learning, Major depressive disorder (MDD), Anxiety.

\section{INTRODUCTION}

Depression is thoughtful consequence that affects every walk of human life. The major grounds of impairement in both males and females is Depression. In 2016, WHO conducted a survey states that load of Depression is $50 \%$ high in females than males. In $\mathrm{r}$ eality, also in both high income and low and moderate income countries depression is major reason of disease concern. As per the Research conducted by Rahman in 2008 maternal depression is a risk component for poor maturation in young children in developing countries. Depression affects social living, family relation, line of work, and one's sense of self-regard and purpose. In women the reason behind depression may be from generative hormones, societal class pressures and reaction of female to strain.

As per the Global Burden of Disease, 2000 [1] Major Depressive Disorder (MDD) is the most frequent psychiatric disorder and Unipolar Depressive Disorder(UDD) is the fourth most popular cause of disability in feminine, of all age groups. The lifespan ratio of Major Depressive Disorder(MDD) is $10-25 \%$ for women, and $5-12 \%$ for men [2]. Depression is second reason of Global Disease Burden by the end of 2020 and it is the major cause for suicide as documented by World Health Organization. and also WHO states that the most prevailing psychiatric disorder is Major Depressive Disorder. For Major Depressive Disorder the life time ratio for women is $10-25 \%$ and for men ratio is $5-12 \%$ [2].According to $\mathrm{WHO}$, the rate of depression is $9 \%, 36 \%$ for major depressive segment and in India normal age for start of depression is 31.9 years[3]

Revised Manuscript Received on Dec 12, 2019.

* Correspondence Author

Mrs. Vidya Y., Dept. of CSE, RNS Institute of Technology, VTU, Bengaluru, India, Email: vidya.yc@gmail.com

Dr G. T. Raju, Dept. of CSE, RNS Institute of Technology, VTU, Bengaluru, India, Email: gtraju1990@yahoo.com

Individuals more than $20 \%$ entering primary health centres are suffering from coupled disorders such as anxiety and depression,specially in developing countries.But the indications of these disorders are oftenly identified. The maximum number of Depression cases specially in women are constanly found in India. In Women at the time of maternity the chances of developing depression is more. In India, females are more prone to Psychotic societal events such as strain, sex specific socialization, deprived social status and so on[9].WHO states that in mumbai depression is more in married females with somatic and emotive symptoms[10].

One quarter to one half of women in their lives are affected by Depression. Compusion must be done for every female patients entering hospital for domestic violence cases must undergo regular screening to avoid damaging physical and mental wellness.As per today's trend almost all the females are employed, which gives them the independence and financial strength. According to the survey done by Associated Chambers of Commerce and Industry, 68\% of employed women belonging to age of 21- 52 years are suffering from depression,prolonged backache, obesity and high blood pressure [13].75\% of working women are prone to depression and anxiety disorders because of extended hours of work under tight deadlines. $53 \%$ of them go for junk food neglecting their meals because of work pressure level and stringent deadlines.The other components which causes depression in women are poisonous substance from environment, pollutants from industries, lack of sunlight exposure,lack of sleep and exercise,malnutrition,intake of dug and alcohol.

Mental sickness is one of the most prevailing so far unnoticed issues. As per WHO, Around twenty percent of adolescents including children and twenty three percent of entire human population are having mental sickness, which makes the neuropsychiatrical disorders the biggest reason for disability [1]. Depression is one of the most prevailing mental health disorder. More than 300 million individuals are estimated to be suffering from depression [2]. Even so, the ratio of depression varies from minimal of 2.6 percent Western Pacific males to a maximal of 5.9 percent African females, by World Health Organization (WHO) gender and region. Even though, depression is more prevelent most of the countries do not have basic facilities in order to get over Depression. According to study, only 87 percent countries provide few primary care for various mental disorders[3]. Less than 10 percent sufferers in the world receives effectual treatments for Depression [4]. 
But, in low and moderate financial gain nations treatment is not reaching to arround 76 to 85 percent of sufferes.Rather, in high financial gain countries 35 to $50 \%$ of patients with depression are deprived of treatment[5] and 30\% countries are lacking specialised program to handle mental wellness. These are some of the reasons which highlights need to develop contemporary methods to idetify the sufferers or one who is more probable to reach depression. In this regard, researchers are on the job of finding new methods to diagnose depression.In 1976, arround 50 percent of patients comes under depressed category at the first start of depressive occurance episode [6].

In 1982, patients were categorised as depressed patients and non depressed patients by oxman after studying their speech. [7]. Brown et al. Conducted studies which demonstrated that lower self-esteem and lack of social support are major causes associated with relative frequency of depression [8]. Two independent studies took place in 2003 which correlated depression with negative psychological feature.One study predicted that, depression from negative psychological feature results in resolving ambiguous verbal information [9].The other method predicted the onset, duration and number of depressive episodes from negative cognition styles and consideration of subjects in response to mental strain [10]. Cloninger summarizes the theatrical role of personality construct in the exposure of start of depression in upcoming work [11].In order to diagnose the depression all these works furnished additional means by applying communication and social media mannerism.

\section{LITERATURE REVIEW}

The primary objective of early detection of depression is identifying users showing signs of depression so that appropriate diagnosis and treatment may follow at the earliest. Depression if untreated may lead to undesirable effects apart from the disease itself, such as increased chances of risky behavior like drug or alcohol addiction, make it difficult to recover from other serious illnesses and the disease itself may be prolonged for years viz clinical depression. Fig 1 shows the worldwide disease burden and number of people affected worldwide by Major Depressive Disorder (MDD) and dysthymia as reported by World Health Organization (WHO) [22]

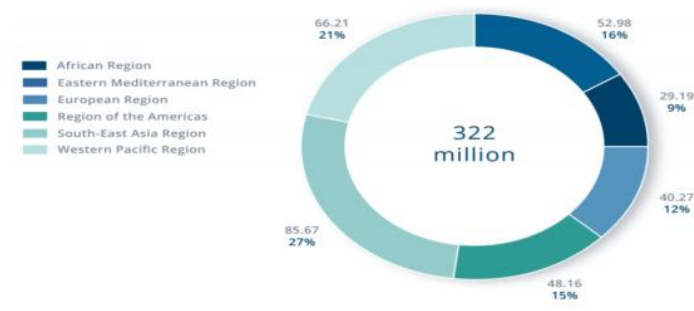

Fig 1. Worldwide Disease Burden

India has more number of suicide cases in 2012 according to WHO followed by every 40 seconds one individual commits suicide.Major cause of diability worldwideis Depression and also it is contributing a lot towards international worry of disease.Chances of depression is more in women than men, which finally leads to suicide.Currently population of India is around one billion citizens. In 2015, the ratio of 1 in 5 Indians are suffering from Depression according to the survey done by Word Health Organization. WHO conducted a survey for NCMH (National Care Of Medical Health), reports that probability of patients suffering from depression in India is around $6.5 \%$. Even though effectual treatments are availiable there is an intense lack of psychologists, psychiatrists, and doctors where theyall comes under mental wellness workers. The number of such workers are "1 in 100,000 individual" as repoted by WHO. The average rate of commiting suicide in India because of depression is about 10.9 for every $1,00,000$ individual and the age of people commiting suicide are below 44 years. Considering this data as reference no doubt in saying the most depressed nation is India.

TLLLF known as The Live Love Laugh Foundation is a charity whose main purpose is to create consciousness with regard to mental sickness and the signs related to depression, focusing on strain, anxiousness and depression. THis Foundation accredited How India Comprehend Mental Health: TLLLF National Survey Report 2018, undersatanding mental wellness viewpoint with a goal of researching perceptions encompassing mental wellness and mental sickness in India. The survey also looks into level of sensitiveness, mental attitude towards mental wellness and also the signs of depression associated with it.

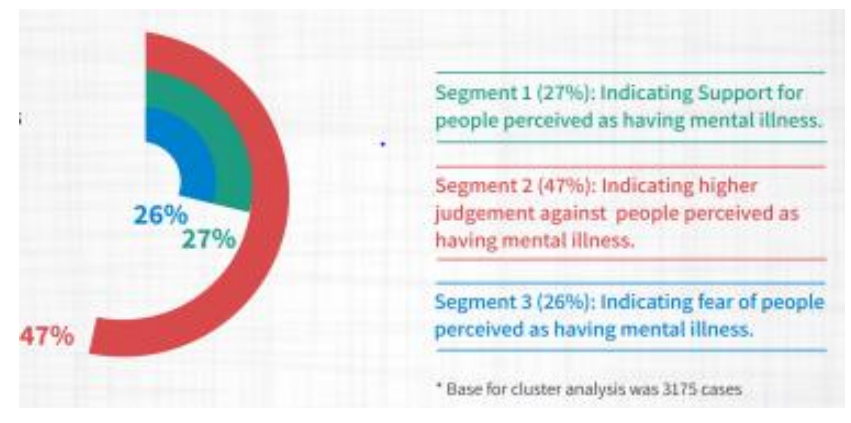

Fig 2 : Suppport, Judgement, Fear chart

The survey reported that while 87 percent of the answerer showed some consciousness of mental sickness, 71 percent also used terms associated with stigma.

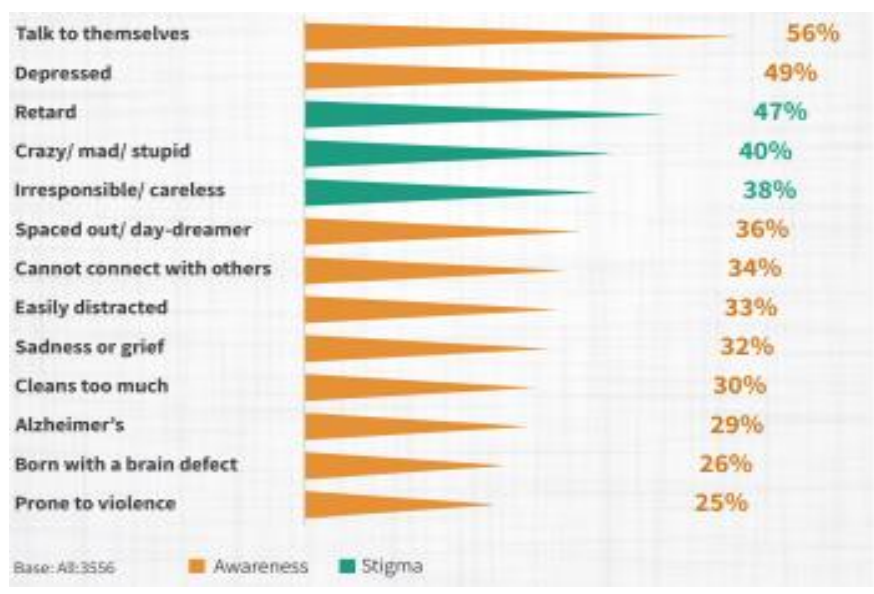

Fig 3 : People's understanding of mental health

Published By: 
Following figure represents 2 different issues they signs and consciousnes of depression.In India, To tackle the load of mental sickness the above issues has to be addressed in parallel. If the people view mental sickness with apprehensiveness and opposition, it becomes difficult for them with mental health care.

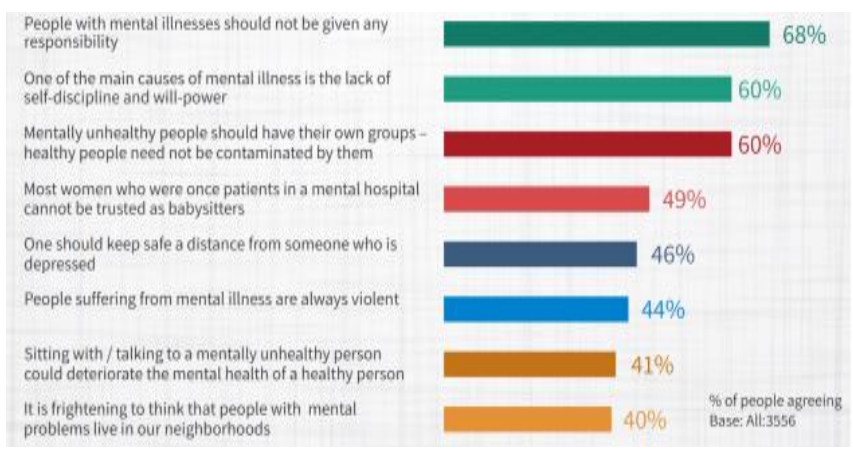

Fig 4 : People's attitudes towards those affected

\section{DATA COLLECTION AND SAMPLING}

Different strategies have been employed by different studies which exploits the necessary Twitter data. Twitter API is used by many studies to acquire public tweets. But the attributes used in studies are differed according to the strategy followed. The dataset which is created for CLPsych 2015 Shared Tasks was straightaway utilised by some studies. The rest either (1) Communicated state of public Twitter for specific period of time along with their approval to suitably identify depressed and non-depressed people. or (2) all public tweets are directly well-mined in English language containing the word "depression" or directly wellmined all public tweets in English language comprising either word "depression". Finding potential subjects right away or online forums may be desirable only for smaller surveys. Amazon's Machine Turk (Turk) interface was used by De Choudhary to conduct large-scale survey on crowd workers [20]. crowd workers was asked to take up standardised clinical depression study along with username of public Twitter profile, depression histroy and their demographics. Later Reece et al. [21] adopted similar approach.Crowd Workers has been asked to take up acceptable clinical depression survey and also to share their depression story, statistical information and username of their Twitter profile. Later similar kind of move was followed by Reece et al. [21], but they removed data samples where the crowd worker tired depleted time in completing the study. As well, auxiliary screening tests were enclosed in the review article to filtrate those entries whose depression scores did not related to much across the scales [20].

Table 1. Details of Datasets used in major studies

\begin{tabular}{|l|l|l|}
\hline Study & Content & size \\
\hline $\begin{array}{l}\text { 2012- Park et } \\
\text { al }\end{array}$ & $\begin{array}{l}\text { 1- Week worth } \\
\text { tweets preceding and } \\
\text { up to date study }\end{array}$ & $\begin{array}{l}\text { (Depressed = 23) } \\
5,706 \text { tweets }\end{array}$ \\
\hline
\end{tabular}

\begin{tabular}{|l|l|l|}
\hline $\begin{array}{l}\text { 2013- De } \\
\text { choudhary et } \\
\text { al }\end{array}$ & $\begin{array}{l}\text { Every tweets posted } \\
\text { from exactly 1 year } \\
\text { before the survey } \\
\text { date (normally) or } \\
\text { first onset of } \\
\text { depressive episode } \\
\text { (for user who } \\
\text { reported depression) }\end{array}$ & 2,157,992 tweets \\
\hline $\begin{array}{l}\text { 2013- Tugawa et al } \\
\text { Tormalized }\end{array}$ & $\begin{array}{l}\text { frequency of words } \\
\text { used in tweets by 50 } \\
\text { users }\end{array}$ & 14,757 words \\
\hline $\begin{array}{l}\text { 2015- } \\
\text { ShPych }\end{array}$ & $\begin{array}{l}\text { Recent 3000 public } \\
\text { tweets per user of } \\
\text { age and gender } \\
\text { matched control } \\
\text { users }\end{array}$ & (Depressed=327) \\
\hline $\begin{array}{l}\text { 2017- Reece } \\
\text { et al }\end{array}$ & $\begin{array}{l}\text { Every participants } \\
\text { twitter post to the } \\
\text { most }\end{array}$ & $\begin{array}{l}\text { 204 users } \\
\text { (Depressed=105) } \\
\text { 279,951 tweets }\end{array}$ \\
\hline
\end{tabular}

\section{CHOICE OF DEPRESSION SCALE}

Almost all the studies employed (CES-D) standard to compute the state of depression which is popularly known as Centre for Epidemiological Studies Depression. In order to measure the state Depression CES-D has 20 long questionnaire. Based on the Score of CES-, the probability of deoression may be low-level (0-15), moderate (16-22) or high- level (23-60) [23]. The threshold value for CES-D score to identify depression choosen by park is 22 in order to maximise particularity and false-positive rate. In the successive studies similar threshold value is used. In addition to this they used Beck Depression Inventory (BDI) as secondary screening. Self-evaluation Depression standard was used by Tsugawa[25].

\section{FEATURE EXTRACTION}

Almost all the surveys proposed their specific approach to extract the feature. Here, are the some of the methods to extract features which are put upon by the major surveys.

1) Park - 2012: Sentiment analysis have been done on tweet textual matter using Linguistic Inquiry Word Count (LIWC), which is a text synthesis program that classify the words into significant classes and sub-classes of multiple psychology.This is followed by returning the scores on the basis of amount of words belonging to its classes and subclasses. Among the received scores, classes with very huge multiple correlation are removed by investigating bivariate correlation in between autonomous variants and condition numbers. The leftover categories were recognized as features for the following step.

2) Tsugawa - 2013: This study made an attempt to implement an approach known as "Bag of Words", which gives us how often the words are put on by the users in tweets as features[25]. 
3) De Choudhary - 2013: Dynamic parameters are developed in their study to classify on the basis of Twitter data behavioral fluctuation between depressed and not depressed . Some of those features are amount,

Response, Retweet, Links, Inquirycentric and Sleep disorder index as criterion of Engagement. Also, Followers, Followees, Reciprocality, Prestigiousness ratio, Graph density, Clustering coefficient, Two-hop locality, Embeddedness and Egotism element as criterion of Egocentric Social Graph.

(ii) Constructive affect (CA), Destructive affect (DA), Stimulation and Dominance as criterion of Feeling.

(iii) Dictionary of Depression and useage of antidepressants are some of the criterion of Depression.

\section{RESULTS AND DISCUSSIONS}

Out of all studies, the common activity is to classify the user as either "depressed" or "not depressed" by using classifier. Even so, some previous studies attempted to determine depression scores by making use of multiple regression [22, 23]. In Supervised learning-based classifiers, the nominal number of tweet elected randomly in order to form the training and experimental datasets. The most commented dataset was Training Dataset.Principal Component Analysis (PCA) was enforced by De Choudhary to prevent over fitting.Followed by this enforcement, Nadeem implementeddiffernt classifiers such as Decision Tree, Logistic Regression, Naïve Bayes and Linear Support Vector which evaluated the opeartion of 4 classifiers.Out of all these classifiers Random Forest classifier produced best results with their data as observed by Reeve et al.[21].Refer Table 3.

Table 2 summerizes five different approaches for supervised learning. Support Vector Machine, Random Forest and GBM has performed than other 2 models Navie Bayes model and KNN.The adaption of different models depends on data characteristics and Navie bayes model and KNN model has improved dependency on the data.In reality it is difficult to forecast which model is works best before before applying the data to models. In few cases, even though huge amount of attributes are measured only very few attributes contribute to solution.In other cases, because of the complexity of Machine Learning moldel over fitting to given data takes place hence it is not suited for unobserved data.To avoid overfitting Simple Machine Learning models are used.Hence the better option to choose the model is to apply the data to all models.Later best working model is choosen,otherwise, careful investigation about the data has to be done to select suitable Machine Learning model.

Table 2: Frequently used machine learning Models in mental health

\begin{tabular}{|c|c|c|}
\hline Models & Merits & Demerits \\
\hline SVM & $\begin{array}{l}\text { In general it gives } \\
\text { comparatively } \\
\text { results }\end{array}$ & $\begin{array}{l}\text { To examine complex data, } \\
\text { detailed data preprocessing } \\
\text { and suitable Kernal is used }\end{array}$ \\
\hline GBM & $\begin{array}{l}\text { In general it gives } \\
\text { comparatively } \\
\text { results }\end{array}$ & $\begin{array}{l}\text { In GBM Raining Learner } \\
\text { takes more time compared } \\
\text { to other models. }\end{array}$ \\
\hline $\begin{array}{l}\text { Random } \\
\text { Forest }\end{array}$ & $\begin{array}{l}\text { The algorithm itself } \\
\text { automatically covers its } \\
\text { previous weakness in } \\
\text { dealing with some }\end{array}$ & $\begin{array}{l}\text { Interpretation between } \\
\text { attributes and target is } \\
\text { complex } \\
\text {-In complex Random } \\
\text { Forest Prediction rate is } \\
\text { comparatively slow. }\end{array}$ \\
\hline Naive bayes & $\begin{array}{l}\text {-Prediction and Training } \\
\text { time is comparitievely } \\
\text { short } \\
\text {-Can provide intermediate } \\
\text { conditional probabilities } \\
\text { of attributes }\end{array}$ & $\begin{array}{l}\text {-Unrealistic assumption: } \\
\text { Attribute independency }\end{array}$ \\
\hline $\mathrm{KNN}$ & $\begin{array}{l}\text { Training procedure is not } \\
\text { needed }\end{array}$ & $\begin{array}{l}\text {-When the amount of data } \\
\text { increases prediction time } \\
\text { period increases rapidly } \\
\text { - Even though if there is } \\
\text { small gain in amount of } \\
\text { features, it has to consider } \\
\text { large data } \\
\text { - The type of Distance } \\
\text { metric to be used is more } \\
\text { dependent. }\end{array}$ \\
\hline
\end{tabular}

Table 3: Different approaches used for Identifying Depression

\begin{tabular}{|c|c|c|c|c|}
\hline Author & Subject & Intent & Approaches & Outcome \\
\hline $\begin{array}{l}2013 \text { Munmum De } \\
\text { choudhary }\end{array}$ & $\begin{array}{l}\text { Social media as } \\
\text { Measurement tool } \\
\text { depression } \\
\text { populations }\end{array}$ & $\begin{array}{l}\text { Measuring } \\
\text { Depression }\end{array}$ & $\begin{array}{l}\text { SVM classifier, centre for } \\
\text { Epidemiologic } \\
\text { Depression studies } \\
\text { social media deale(CES-D), } \\
\text { index(SMDI), depression } \\
\text { Component Analysis(PCA) }\end{array}$ & $\begin{array}{l}\text { SMDI can nearly } \\
\text { reflect } \\
\text { characterized insights } \\
\text { on depression }\end{array}$ \\
\hline Richard Socher et & $\begin{array}{l}\text { Recursive } \\
\text { models foe semantic } \\
\text { compositionality over } \\
\text { a sentiment Treebank }\end{array}$ & $\begin{array}{l}\text { Predicting } \\
\text { Depression }\end{array}$ & 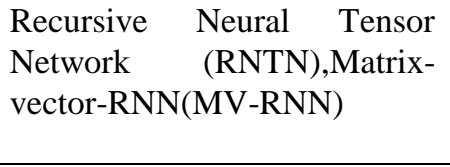 & $\begin{array}{l}\text { RNTN obtains } 80.7 \% \\
\text { accuracy }\end{array}$ \\
\hline
\end{tabular}




\begin{tabular}{|c|c|c|c|c|}
\hline $\begin{array}{l}\text { 2014- Munmum } \\
\text { De choudhary }\end{array}$ & $\begin{array}{l}. \text { Use of Shared } \\
\text { Facebook Data to } \\
\text { characterize and } \\
\text { predict Depression } \\
\end{array}$ & $\begin{array}{l}\text { Predicting } \\
\text { Postnatal } \\
\text { Depression }\end{array}$ & $\begin{array}{ll}\text { Patient } & \text { Health } \\
\text { Questionnair(PHQ-9),LIWC }\end{array}$ & $\begin{array}{lr}\text { Prediction } & \text { of } \\
\text { postnatal Depression } \\
\text { was best. }\end{array}$ \\
\hline $\begin{array}{l}\text { 2015- Pete } \\
\text { Burmapet }\end{array}$ & $\begin{array}{l}\text { Analyzing } \\
\text { communication related } \\
\text { to suicide and } \\
\text { Machine } \\
\text { Classification } \\
\text { Twitter Data }\end{array}$ & $\begin{array}{l}\text { Identification } \\
\text { and } \\
\text { Classification } \\
\text { related to } \\
\text { suicide }\end{array}$ & $\begin{array}{l}\text { Term frequency inverse } \\
\text { document frequency(TF- } \\
\text { IDF),Linguistic Inquiry and } \\
\text { Word Count(LIWC),Principal } \\
\text { Component Analysis,Support } \\
\text { Vector Machine(SVM),Rule } \\
\text { BAsed,Naiver Bayes,J48 } \\
\text { Decision Tree,Rotation Forest }\end{array}$ & $\begin{array}{l}\text { Results achieved an } \\
\text { F-Measure og } 0.728 \\
\text { overall } \\
0.69 \text { for suicidal } \\
\text { ideation class }\end{array}$ \\
\hline $\begin{array}{l}\text { 2016- Scott } \quad R . \\
\text { Braithwaite }\end{array}$ & $\begin{array}{lr}\text { Validating } & \text { Machine } \\
\text { Learning Algorithm } \\
\text { for Twitter Data } \\
\text { Against } & \text { Established } \\
\text { Measures } & \text { of } \\
\text { Suicidality } & \end{array}$ & $\begin{array}{l}\text { To validate } \\
\text { Machine } \\
\text { learning } \\
\text { algorithms to } \\
\text { predict suicide } \\
\text { risks }\end{array}$ & $\begin{array}{l}\text { Depressive } \\
\text { Inventory-Suicide } \\
\text { Subsale(DSI_SS),Interpersona } \\
1 \text { needs Questionnair(INQ), } \\
\text { and Acquired capability for } \\
\text { suicide Scale(ACSS), LIWC: } \\
\text { updated } 2015 \text { version, Scikit- } \\
\text { learn library,Decision tree } \\
\text { Learning }\end{array}$ & $\begin{array}{l}\text { The outcome } \\
\text { characterized the } \\
\text { people who are at } \\
\text { suicide risk and who } \\
\text { are not with the help } \\
\text { of Machine Learning } \\
\text { Algorithms. }\end{array}$ \\
\hline $\begin{array}{l}\text { 2017- Elvis } \\
\text { Saravia }\end{array}$ & $\begin{array}{l}\text { Using social Media to } \\
\text { identify and analyse } \\
\text { Mental sickness }\end{array}$ & $\begin{array}{l}\text { To predict } \\
\text { Depression }\end{array}$ & \begin{tabular}{lr} 
Center for & \multicolumn{2}{c}{ Epidermologic } \\
studies depression & scale,TF- \\
IDF,PLF,Sentiment & \\
140API,Random & Forest \\
$\begin{array}{l}\text { Classifier:a main } \\
\text { model }\end{array}$ &
\end{tabular} & $\begin{array}{l}\text { Online system was } \\
\text { established that takes } \\
\text { out } \\
\text { characteristics and } \\
\text { gave minimum results } \\
\text { by taking into account } \\
2 \text { mental } \\
\text { disorders.Later this is } \\
\text { used as reference to } \\
\text { predict behaviour of } \\
\text { user } \\
\text { effectievely. more }\end{array}$ \\
\hline 2016- Keumhee & $\begin{array}{lr}\text { To } & \text { Identify } \\
\text { Depressive users in } \\
\text { Twitter Multimodal } \\
\text { analysis }\end{array}$ & $\begin{array}{l}\text { Extracts } \text { Tweets } \\
\text { from Twitter } \\
\text { that indicate } \\
\text { Depression }\end{array}$ & $\begin{array}{l}\text { SVN based Learning, Built a } \\
\text { Lexion by using Visual } \\
\text { Sentiment Ontology and } \\
\text { Sentistrength } \\
\text { dictionaries,LIWC,K-means } \\
\text { Clustering Latent Fusion }\end{array}$ & $\begin{array}{l}\text { The results shows that } \\
\text { a multimodal that is } \\
\text { developed has high } \\
\text { accuracy as compared } \\
\text { to the existing } \\
\text { methods, and can } \\
\text { efficiently predicts the } \\
\text { user's mood }\end{array}$ \\
\hline $\begin{array}{l}\text { Maryam } \\
\text { Mohammed } \\
\text { Aldarwish } \\
\text { et.al.,(2017) }\end{array}$ & $\begin{array}{l}\text { Predicting Depression } \\
\text { Levels using social } \\
\text { Media posts }\end{array}$ & $\begin{array}{l}\text { Classification of } \\
\text { users according } \\
\text { to mental Illness }\end{array}$ & $\begin{array}{l}\text { BDI-II Questionnair, create a } \\
\text { depression model using } \\
\text { RapidMiner,SVM and Naive } \\
\text { Bayes classifier }\end{array}$ & $\begin{array}{l}\text { The performance of } \\
\text { the model is } \\
\text { calculated and they } \\
\text { got the best precision } \\
\text { and minimal accuracy } \\
\text { and recall }\end{array}$ \\
\hline $\begin{array}{l}\text { 2017- Adrain } \\
\text { Benton }\end{array}$ & $\begin{array}{lr}\text { Multitasak } & \text { Learning } \\
\text { for Mental } & \text { Health } \\
\text { conditions } & \text { with } \\
\text { Limited Social Media } \\
\text { data }\end{array}$ & $\begin{array}{l}\text { Predicting } \\
\text { Depression }\end{array}$ & $\begin{array}{lr}\begin{array}{l}\text { Multitask } \\
\text { approach(MTL), }\end{array} \begin{array}{r}\text { Learning } \\
\text { Logistic } \\
\text { Regression, Feedforward } \\
\text { multilayer perceptron Single } \\
\text { task Learning(STL) }\end{array} \\
\end{array}$ & $\begin{array}{lr}\text { Results shows that the } \\
\text { proposed } & \text { model } \\
\text { performs } & \text { better } \\
\text { comparedto } & \text { LR } \\
\text { models. } & \\
\end{array}$ \\
\hline
\end{tabular}




\begin{tabular}{|c|c|c|c|c|}
\hline $\begin{array}{l}\text { 2018- Yoshihiko } \\
\text { Suhara }\end{array}$ & $\begin{array}{l}\text { DeepMood: } \\
\text { Forecasting Depressed } \\
\text { Mood based on Self- } \\
\text { Reported Histories via } \\
\text { Recurrent Neural } \\
\text { Networks }\end{array}$ & $\begin{array}{l}\text { Predicting } \\
\text { Depressed } \\
\text { moods }\end{array}$ & $\begin{array}{lr}\text { Long short term } & \text { memory } \\
\text { recurrant } & \text { neural } \\
\text { networks,Utrsureko: } & \text { a } \\
\text { smartphone } & \text { application, } \\
\text { Ecological } & \text { momentary } \\
\text { assesment(EMA) } & \text { approach }\end{array}$ & $\begin{array}{l}\text { The outcome } \\
\text { highlited developed } \\
\text { model predicts intense } \\
\text { depression on the } \\
\text { basis of user histroies } \\
\text { and produces more } \\
\text { accuracy }\end{array}$ \\
\hline
\end{tabular}

\section{CONCLUSION}

The aim of this paper is to furnish information about primary concepts of ML algorithms that are frequently used in mental health field and their real application instance in this area. Study of mental wellness using different Machine Learning approaches are primarily centred on supervised learning for classifications. According to our review depression, PTSD, schizophrenia,, ASD, bipolar disease as domains where ML techniques were applied in mental health, and SVM, GBM, Random Forest, KNN, Naïve Bayes have been applied in these domains.According to our review, differnt Machine Learning approaches were employed as discussed in table 2 in mental health to predict depression. Every model has its own merits and drawbacks. The performance of all these models relays on different properties of data and intent of study. Since lot of human preprocessing on Machine Learning models such as data preprocessing, tuning of models in order to fit into optimality, it is difficult to quote that one particular model is best for every areas at all times. Researchers examine their data with different classifiers in order to select the best classifier which results in maximum accuracy.The leading scope for future evolution lies in finding the new method to automate the process of identifying the depression which generates the reports on a regular basis. We have to work to get better algorithms in future since techniques used in Natural Language Processing(NLP) is newfound and is still in developing stage. And also accuracy of these algorithms need to be maximized in order to use with large- scale data

\section{REFERENCES}

[1] World Health Organization (WHO), "10 Facts on Mental Health," World Health Organisation, 2015

[2] World Health Organization, "Depression and other common mental disorders: global health estimates," 2017.

[3] R. Detels and C. C. Tan, "The Scope and Concerns of Public Health," Oxford Textb. Glob. Public Heal., vol. 1, pp. 3-18, 2015.

[4] World Health Organization (WHO), "Depression (Fact Sheet)," World Health Organisation, 2017. [Online]. Available: http://www.who.int/mediacentre/factsheets/fs36 9/en/. [Accessed: 31-Dec2017].

[5] S. W. H. Assembly, "The global burden of mental disorders and the need for a comprehensive, coordinated response from health and social sectors at the country level," Sixty-fifth World Health Assembly, no. May, pp. 2-5, 2012.

[6] G. Winokur, "Duration of Illness before Hospitalization (Onset) in the Affective Disorders," Neuropsychobiology, vol. 2, no. 2- 3, pp. 87-93, 2008.

[7] T. E. Oxman, S. D. Rosenberg, and G. J. Tucker, "The language of paranoia,” Am. J. Psychol., 1982.

[8] G. W. Brown, B. Andrews, T. Harris, Z. Adler, and L. Bridge, "Social support, self-esteem and depression.," Psychol. Med., vol. 16, no. 4, pp. 813-31, 1986.

[9] S. S. Rude, C. R. Valdez, S. Odom, and A. Ebrahimi, "Negative Cognitive Biases Predict Subsequent Depression," Cognit. Ther. Res., vol.
27, no. 4, pp. 415-429, 2003

[10] M. S. Robinson and L. B. Alloy, "Negative cognitive styles and stressreactive rumination interact to predict depression: A prospective study," Cognit. Ther. Res., vol. 27, no. 3, pp. 275-291, 2003.

[11] C. R. Cloninger, D. M. Svrakic, and T. R. Przybeck, "Can personality assessment predict future depression? A twelve-month follow-up of 631 subjects," J. Affect. Disord., vol. 92, no. 1, pp. 35-44, 2006.

[12] S. Vazire and S. D. Gosling, "e-Perceptions: Personality impressions based on personal websites," J. Pers. Soc. Psychol., vol. 87, no. 1, pp. 123 $132,2004$.

[13] J. W. Pennebaker, M. R. Mehl, and K. G. Niederhoffer, "Psychological Aspects of Natural Language Use: Our Words, Our Selves," Annu. Rev. Psychol., vol. 54, no. 1, pp. 547-577, 2003.

[14] P. Resnik, A. Garron, and R. Resnik, "Using Topic Modeling to Improve Prediction of Neuroticism and Depression in College Students," Proc. 2013 Conf. Empir. Methods Nat. Lang. Process., no. October, pp. $1348-1353,2013$.

[15] M. A. Moreno et al., "Feeling bad on Facebook: Depression disclosures by college students on a social networking site," Depress. Anxiety, vol. 28, no. 6, pp. 447-455, 2011.

[16] H. A. Schwartz et al., "Towards Assessing Changes in Degree of Depression through Facebook," Proc. Work. Comput. Linguist. Clin. Psychol. From Linguist. Signal to Clin. Real., pp. 118-125, 2014.

[17] Shannon Greenwood, Andrew Perrin, and Maeve Duggan, "Demographics of Social Media Users in 2016 | Pew Research Center," Pew Research, 2016. [Online]. Available: http://www.pewinternet.org/2016/11/11/socialmedia-update-2016/.

[Accessed: 01-Jan-2018].

[18] J. Mikal, S. Hurst, and M. Conway, "Ethical issues in using Twitter for population-level depression monitoring: A qualitative study," BMC Med. Ethics, vol. 17, no. 1, 2016.

[19] R. Kotikalapudi, S. Chellappan, F. Montgomery, D. Wunsch, and K. Lutzen, "Associating internet usage with depressive behaviour among college students," IEEE Technol. Soc. Mag., vol. 31, no. 4, pp. 73-80, 2012 .

[20] M. De Choudhury, M. Gamon, S. Counts, and E. Horvitz, "Predicting Depression via Social Media," Proc. 7th Int. AAAI Conf. Weblogs Soc. Media, vol. 2, pp. 128-138, 2013.

[21] A. G. Reece, A. J. Reagan, K. L. M. Lix, P. S. Dodds, C. M. Danforth, and E. J. Langer, "Forecasting the onset and course of mental illness with Twitter data," Sci. Rep., vol. 7, no. 1, pp. 1-11, 2017.

[22] T. K. Houston, L. A. Cooper, H. T. Vu, J. Kahn, J. Toser, and D. E. Ford, "Screening the Public for Depression Through the Internet,"Psychiatr. Serv., vol. 52, no. 3, pp. 362-367, 2001.

[23] B. A. Husaini, J. A. Neff, J. B. Harrington, M. D. Hughes, and R. H Stone, "Depression in rural communities: Validating the CES-D scale," J. Community Psychol., vol. 8, no. 1, pp. 20-27, 1980.

[24] Park Minsu, Chiyoung Cha, and Meeyoung Cha, "Depressive Moods of Users Portrayed in Twitter," ACM SIGKDD Work. Healthc. Informatics, pp. 1-8, 2012.

[25] S. Tsugawa et al., "On estimating depressive tendencies of Twitter users utilizing their tweet data," Proc. - IEEE Virtual Real., 2013.

[26] M. Nadeem, M. Horn, and G. Coppersmith, "Identifying Depression on Twitter," CoRR, pp. 1-9, 2016.

[27] A. Ritter, S. Clark, Mausam, and O. Etzioni, "Named Entity Recognition in Tweets: An Experimental Study," Proc. 2011 EMNLP (EMNLP 2011), pp. 1524-1534, 2011. 


\section{AUTHORS PROFILE}

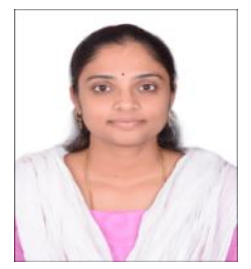

Mrs. Vidya Y currently working as Assistant Professor, Dept. Of CSE, RNSIT. She has an overall of 8 years teaching experience. She has been awarded her M.tech and B.E degrees in Computer Science and Engineering from Visvesvaraya Technological University in 2012 and 2009 respectively. She has presented 3 papers in national conferences. Her research interests are Machine Learning, Artificial Intelligence, Deep Learning, Big Data.

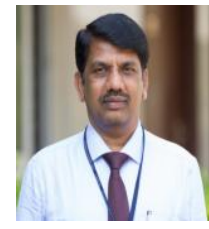

Dr G T Raju currently working as Vice-Principal and Head of CSE Dept. RNSIT. He has 25+ years of teaching and $12+$ years of research experience. $\mathrm{He}$ has published 55 papers in international Journals, conferences. $\mathrm{He}$ has organized 28 workshops/FDP/conferences \& delivered 30 invited talks. He has received 21 lakhs research grants from

AICTE and VTU . He is life member of ISTE and CSI. His research interests are pattern recognitions, web mining, image processing \& information retrieval, machine learning and artificial intelligence. He has held various positions at university. 